\title{
Study on Cultural Difference and Integration in the Process of Localization of Translational Enterprise
}

\author{
Wu Xiao ${ }^{1, a}$, Li Haiming ${ }^{2, b}$ \\ ${ }^{1}$ Department of Business Administration, Chongqing College of Finance and Economics, \\ Chongqing, 402160, China \\ ${ }^{2}$ College of Economics and Management, Southwest University, Chongqing, 400715, China \\ aemail: 670734713@qq.com, bemail: Ihm2@sina.com
}

Keywords: Filed Research; Culture Statement; Course of Localization; Cultural Difference and Integration

\begin{abstract}
Based on facts and relevant articles, this paper collected and systemized the cultural difference between Chinese and Swedish employees at work as well as the enterprise culture statements understood by them respectively. Then, from the perspective of joint venture enterprise culture comprehended by Chinese side, this paper mainly discusses and analyzes the culture statement of joint venture enterprise by China and Switzerland to judge the degree of localization influence on the enterprise as well as the concrete manifestation of differences in both sides' cultures during the process of integration and to explore a development road, which is beneficial to both sides, via classification, systemization and comparison.
\end{abstract}

\section{Introduction}

To understand the management concepts of China and Switzerland, we need to turn to the cultures of the two countries. "Culture" is the spiritual source rooted in a country and nation, so different countries have different understandings about culture. However, there is no doubt that there is a basic consensus about the description of "culture". Culture, which includes some similar elements, is the sum of common value, faith and manners, and is also a strongly subjective synthesis with steady group features. Boyes thinks that, according to the analysis from the perspective of managerial economics, enterprise culture is a low-cost method for building and strengthening a contract, cooperation and trust, so a good enterprise culture can save transaction expenses, reduce communication costs, strengthen the common goals and improve efficiency. All of these have already become hard-won strategic assets.

Thus, the managerial behavior psychology research mainly focuses on discussing the commonality and difference among varied cultures to differentiate the real cultural differences and superficial phenomenon, analyze how to avoid and alleviate the errors and conflicts caused by cultural difference in management, and propel the organizational cooperation, creation etc. by using multi-culture resources (Chen Xiaoping, 2008).

Now that we encounter a series of problems in the process of exploring the localization of joint venture enterprise from the perspective of our cultural difference and integration, we have two bases for selection, which are the basis of the parent company and local enterprise culture and the basis of the local culture of the place of joint venture enterprise. The analytical conclusions in the existing articles are dominated by the culture of the joint venture partner, i.e. Volvo, because Volvo's own brand value lasts for 80 years. From the practice of joint venture enterprise, the primary mission of a local company is to form a firm trust relationship with Volvo and build a cooperative culture of seeking common points while reserving difference.

Based on referring relevant articles, this paper deeply digs into the work done by the transnational enterprise in the course of localization by using field visit and investigation from the leadership, teamwork, feedback, skill training and other modules. This paper discusses and analyzes Volvo car's localization in Chengdu, China and discusses the cultural conflicts in the joint venture enterprise and ways of integrating cross-cultural problems from cultural statements in the hope of 
making a contribution to promoting and deepening the study on the management control system (MCS) of joint venture enterprise by collecting and systemizing respective cultural statements from different countries (mainly from China and Switzerland) and by statistically comparing the similarities and differences.

This paper includes parts: part 1 summarizes the enterprise cultures of Geely and Volvo; part 2 is the design of interview content; part 3 is enterprise's cultural comparison; part 4 is to study the enterprise culture integration; the final part is to conclude and summarize the research finding and limitations of this paper.

\section{Overview of Geely and Volvo's Enterprise Cultures}

\section{(1) Course of mergers and acquisitions}

In March 2010, Geely Automobile and Ford Auto officially reached an agreement to purchase $100 \%$ stock rights of Volvo, a Swedish automobile enterprise, at a price of USD 1.8 billion, marking that a privately-operated automobile enterprise finally realized the dream of becoming a transnational enterprise after previous preparations.

After acquisition, Geely Group continues maintaining Volvo's existing management team, doesn't close Volvo's plan of assembling factories and other factories in Switzerland and Belgium, and also doesn't plan to reduce the staff. In the early stage of negotiation, Geely promised neither to change the headquarters in Goteborg, Switzerland nor to change the research and development center.

(2) Statement of enterprise culture

Next, Geely will be China's local enterprise representative and Volvo will be Switzerland's enterprise representative to make their own enterprise culture statements respectively and to systemize both sides' cultures so that people can better understand the cultural difference in a Sino-Swiss automobile enterprise and can know both ourselves and the adversaries.

Greely Holding Group Co., Ltd., which is one of the top ten enterprises within the industry of China, has developed rapidly by virtue of its flexible operational mechanism and continuous independent innovation over the less than 20 years after it entered into the car field. The company launched five great sub-brands, representing varied brand appeals. With regard to the enterprise's cultural development direction, the guiding ideology of humanized spiritual management and militarized efficient execution is implemented in the hope of producing the most safe, most environmentally friendly and most energy-saving cars to make Geely automobile well-known to all the world. Thus, we can see Geely's determination of seizing the market as well as its consideration of situation. In 2007, Geely set about strategy transition, trying hard to complete the strategy transition from pure low cost to high technology, high quality, high efficiency and internationalization for 3 to 5 years. Nowadays, Geely has been international and achieved its strategic goal.

Volvo, which was also called "Fuhao (rich people)" in Chinese, was originally the biggest automobile enterprise in Northern Europe as well as the largest industrial enterprise group in Switzerland and occupied the international market with its most safe, high-quality and environmentally friendly car making concept and the most exciting car experience. Founded in 1927, the company aimed at producing the most desirable and successful top cars of the world.

The specific performances are as follows: Volvo doesn't place the pursuit of sales volume in the first place but insists on manufacturing the "most safe cars in the world". However, Geely is a privately-owned automobile enterprise in a country with high-speed development of economy and taking sales volume as its life, but Geely, as a “cost killer” won't change Volvo's brand and technology to enhance the sales volume.

We can find from the above-mentioned enterprise culture statements that even though their historical and cultural backgrounds are very different, they have the common pursuits of firmly grasping target customers, building brand values and occupying market shares. 


\section{Design of Interview Content}

In order to learn the influences of cultural differences between China and Switzerland, the Chinese side chose more than 10 team managers and employees of local enterprise for interview, which lasted for one week. A large quantity of first-hand materials obtained from investigations are sufficient to explain that the problems caused from mutual collision of Chinese and foreign cultures indeed exist in the daily management practices of a joint venture enterprise. The interview was mainly based on the problems below:

\section{(1) Investigation of leadership}

Everyone has his own different understanding of a good leader, but most of the interviewees have the consensus that a good leader shall be goal-oriented and has the charm of a leader. Before the field enterprise interview, we also pointedly interviewed 4 university students, who were about to stepping into the society. They thought an excellent leader shall be easy-going, scrupulous in separating public from private interests and able to harmonize the interests of all aspects. Besides, a good leader shall also be a good listener according to the employees’ statements.

\section{(2) Employees' opinions and feedbacks}

Establish the enterprise's management and communication mechanism to expand the communication channel. As for feedbacks and other problems during our field survey, the Swedish employees tend to directly communicate with their superiors face to face regardless of positive or negative feedback in the communication information, while Chinese employees scruple and use varied ways for feedbacks during the process of working information feedback, such as using anonymous mailbox (accounting for $10 \%$ of the interviewees), emails etc. It is because the deep-rooted face-saving theory in Chinese culture. However, at present, the weekly meeting is the communication way, which is accepted and mostly used by both sides.

Take meeting communication as an example. China and Switzerland are obviously different. As for the manifestation forms, Swedish employees are more open-minded and free to talk everything and also prefer to deeply discuss details; certainly, this causes a waste of time and low talk efficiency at a meeting; Chinese employees are more cautious, tend to talk something of a clear guiding significance and prefer to solve a problem in a short time. Thus, to solve the communication problem in the enterprise, in the final analysis, it is required to understand both sides' cultural differences, construct a tolerant communication environment and use the easily acceptable communication ways to promote employees to walk out of their own closed social, working and living circles. In addition, choose the management personnel, who not only have good professional ethics, technological knowledge and management ability but also have strong communication and coordination ability and are good at friendly cooperating with people from different cultural backgrounds. When designing the organization structure, pay attention to the design of communication channels such as forming institutionalized, multi-dimensional, formal and informal communication mechanism. Only ceaseless communications can achieve both sides' trust and understanding, and finally form the real cultural integration and innovation.

\section{(3) Teamwork}

Most of the interviewees (including the management personnel and employees) have the teamwork experience; even some of them has the teamwork experience in transnational enterprises. We know that, in daily work, Volvo has the Swedish team, the team composed of Chinese employees and, of course, the transnational team composed of a few of members from other countries. They jointly complete a project or do it crossways. However, cultural conflicts and collision of working thinking habits also happen in specific practical work. The case below can show a segment of a whole.

\section{(4) Cross-culture and skill training}

We can see that management layers and employees from different cultural backgrounds have different corporate values in a transnational enterprise. They are proud of their own countries' cultures but cannot understand or agree with the cultures in other countries. According to this, it is an indispensible course to cultivate employees' common enterprise value in Volvo, a "mixed" company. In our opinion, to build the value of mutual trust and benefit, it is required to eliminate 
the racial superiority at first, respect and understand the cultures of each other, equally communicate with each other, find out two types or more cultural binding points, give full play to both sides' cultural advantages and gradually build a common value in the enterprise. Namely, find a way to develop and keep Volvo's lead-edge technologies in China and even in the world, and actively expand the brand's market in China. Then, there will be breakthroughs for all cultural collisions. After the baptism of foreign cultures, the management layer and employees will blend into the collective; both sides will strengthen their cooperative willingness; the common enterprise value will gradually become the core team culture synthesis; a unified value system built will finally guarantee the continuity in the enterprise's operation and management, effectively stimulate the employees' enthusiasm, and create a harmonious working atmosphere.

\section{Comparison of Enterprise Cultures}

Based on the interview above, we can comparatively analyze the Chinese and Swedish enterprise cultures:

\section{(1) Difference in personnel pay and conditions}

During the interview, we learned that there was a strong legal protection awareness in Switzerland. As specified in the Swedish law, the employees enjoy a paid annual leave for 6 weeks (except for the normal festivals and holidays). This treatment cannot be changed; otherwise, the enterprise will violate the law. However, in China, the employees can only enjoy a paid annual leave for 15 days at most and the paid annual leave is calculated based on different working years; a common employee only enjoys a 5-day paid annual leave when he/she worked for more than one year. In the Chinese team manager's opinion, the paid annual leave for 6 weeks certainly will affect the team's work progress due to the Swedish employees' clear division of labor and basically low possibility of work substitute.

\section{(2) Difference in the sense of time and efficiency}

According to an interviewee's statement during a dialogue in an interview, the time and efficiency problems are repeated several times at meetings. The Chinese manager prefers to arrange the general work and point out the general directions, neglecting the details, while the Swedish manager prefers to focus on the details and hopes to solve a series of problems in the meeting. Thus, the Chinese employees think the meeting efficiency is low.

\section{(3) Difference in the way of thinking}

As is well known, Volvo Automobile is world-renowned for its advanced technologies and superior quality. Their specialized technologies and systemized management mode open door of exploring superior car making knowledge for us. However, time will tell whether the fixed system can be more outstanding in the localization process. In contrast, Geely and other local enterprises can open the international market because of their acute market sense and flexible competition strategies. It will be a win-win game if both sides can learn from each by making the best of both sides' advantages.

\section{(4) Difference in power distance}

There is a short power distance among Swedish people. In Swedish society, there are no obvious differences in their grades and wealth. For example, no security guards are provided in the Swedish government office building and many ministers even go to work by bike. However, China is a country with a long power distance. This has something to do with China's culture, which was formed for several thousand years. Chinese culture stresses social order, hierarchy and distance among people regardless of the three principles and five virtues and the distance between a ruler and his ministers claimed by Confucius and Mencius and the older superior and younger inferior stressed in modern society. For this reason, there is an obvious difference in this aspect between the two countries.

\section{5 .Enterprise Culture Integration}

How to effectively achieve the enterprise culture integration in the course of localization of 
Volvo? We think that it is necessary to make cross-cultural integration and innovation based on understanding the local market of China.

\section{(1) Localization operation}

In our opinion, the Chinese employees are more familiar with Chinese market, so Volvo must get familiar with the local market in China when transplanting its several production lines to Chengdu, China. Actually, the course of localization has been quietly put on the agenda. During the field factory interview, more than half of employees mentioned the cultural difference during the local purchase. One of the interviewee gave a living example in work. In China, you can only spend RMB 2 in buying a bottle of common mineral water; even a bottle of mineral water packaged in a high-end way can only be sold at a price of RMB 4. However, Volvo's purchasing staff prefer to spend RMB 10 to by a bottle of mineral water. Can only such a "high price" meet Volvo's value of high quality? After China joined WTO, the automobile's internationalization has been quickened continuously. As Roland Berger said: After joining the WTO, China will gradually turn into a production base for global auto parts industry and the Chinese-funded component suppliers will make efforts to access the global purchase network for automobile manufactures by utilizing the advantage of low cost. Such a prediction has been realized in China now, but we encounter cultural differences in specific operations.

As mentioned above, we merged Volvo, which accepted the acquisition conditions proposed by China largely because of its strategic consideration of China's future market and low cost. Now that Volvo has entered into China, a rapidly developing market, we should also consider to not only continue using Volvo's good market channels but also inject more localized purchases and production strategies. Such a benign development is the both sides' common interest appeal.

\section{(2) Cultural integration}

The basic treatment modes of cross-national management mainly fall into the following types: the first type is the overstepping mode, which is characterized by a culture in an organization suppressing other cultures and both the enterprise's organizational decision making and behaviors being governed by such culture. This mode can be used when there is a great disparity between cultural powers or when a weak company culture fully accepts the powerful company culture. However, this mode is likely to cause the weak culture group to feel antipathic and the company cannot widely learn from other cultures' strong points, so it will finally aggravate cultural collision. The second type is the compromise mode, where an enterprise use both the home country's culture and the host country's culture together, reserve their own cultures and pursue harmony and stability. However, such mode can only solve the superficial problems with all kinds of inevitable potential dangers. Only when the differences between different cultures are reduced, such cross-cultural management mode can be adopted. The third type is the integration mode. Build a bran-new enterprise culture based on the cultures of parent company and host country by effectively integrating both sides' cultures and promoting the mutual understanding, respect and integration of different cultures by all means. This kind of new culture, which differs from any other kind of culture and reserves the excellent and desirable parts of their cultures respectively, is the organic combination of two cultures. Meanwhile, this mode as strong stability, so enterprises shall implement it according to various situations. The fourth type is transplanting mode. Mechanically apply their respective cultures together by inflexibly transplanting the home country's cultures as well as the host country's culture. This mode will result in the non-acclimatization of both cultures, only cause both sides become mutually exclusive, and finally lead to the inappropriate cultural integration.

Therefore, we clearly realize the necessity and importance of cultural integration but we still need a broad mind about mode selection during the concrete implementation process.

\section{Conclusion}

In the author's opinion, cultural estrangement is a complicated concept including most of irrational factors. The preceding part of the paper mostly mentioned how to mutually integrate the cultures of two or more different nations through institutional improvement so as to get rid of the 
collision of values.

Volvo is a luxury automobile brand with a long history and the essence of the brand lies in the safe and excellent body design. Geely's core competitiveness is "cost killer" instead of brand and technologies. Does Geely change the gene of Volvo to enhance the sales volume because of its famous reputation? The answer is clear that Geely merged Volvo but wholeheartedly wants to respect Volvo's culture, including their talents and technologies. According to the "I love you" by $\mathrm{Li}$ Shufu, I believe that the Swedish people has understood his sincerity.

Besides, different national conditions give birth to different enterprise cultures and commercial customs. After analyzing many transnational enterprise cases, it is not difficult to find that a conflict comes from the strong labor union of the merged company at first; however, basically, there is not a real concept of labor union truly representing the employees in the enterprise of China. Moreover, the increasingly fierce market competition in China causes the employees' working overtime become normal. However, since the western countries have been generally in the post-industrial age with a perfect social security system and a living standard, which is usually ten times or twenty times of China's living standard, their citizens more focus on living quality and the pursuit for amenity of life. For this reason, in the western countries, citizens' right of rest is protected by law. In addition, the foreign enterprise's employees lack spiritual communications with the local people because many of their communications all rest on the superficial aspects. It is not only because of the language communication barriers but also because of the existence of cultural differences.

To sum up, it is necessary to build a "unified culture" system from a "multi-culture" system. When seeking cultural differences, pay more attention to seeking common points while reserving difference. As cultural integration is a long-term process, we can provide continuous trainings and select the professionals with the working experience in a transnational enterprise to keep the long-lasting renewal and development of company.

\section{Acknowledgement}

Supported by Youth Project of National Social Science Funds (13CJL003), the Fundamental Research Funds for the Central Universities (SWU1309369).

\section{References}

[1] Xiaoping Chen, Cross-cultural Management[M]. Tsinghua University Press, 2005.

[2] William Boyes(translated by Liu Wei), New Management Economics[M]. Chinese Market Press, 2005.

[3] Xiaotong Fei, Ideological Source and Practical Significance of Cultural Self-consciousness, China Economic Times, February 1, 2008.

[4] Roland Berger, Ten Greatest Predictions: 10 Main Trends for the Development of Chinese Automobile Industry after China Joined WTO [R/OL] Guoyan Web.

[5] Timur Kuran. William H. Sandholm. Cultural Integration and Its Discontents. Review of Economic Studies, 2008, 75 (1): 201-228. doi: 10.1111/j.1467-937X.2007.00469.x 